PREHOSPITAL CARE

\title{
Dextrose $10 \%$ or $50 \%$ in the treatment of hypoglycaemia out of hospital? A randomised controlled trial
}

\section{Moore, M Woollard}

See end of article for authors' affiliations

Correspondence to: C Moore, Welsh Ambulance Services NHS Trust, Blackweir Ambulance Station, North Road, Cardiff, CF10 3DX, UK; chris.moore@ ambulance.wales.nhs.uk

Accepted for publication 29 December 2004
Objective: To investigate whether 10\% dextrose given in $5 \mathrm{~g} \mathrm{(50} \mathrm{ml)} \mathrm{aliquots} \mathrm{is} \mathrm{more} \mathrm{effective} \mathrm{than} 50 \%$ dextrose given in $5 \mathrm{~g}(10 \mathrm{ml})$ aliquots in the treatment of out of hospital hypoglycaemia.

Design: Randomised controlled trial.

Setting: Out of hospital patients attended by paramedics from a large UK ambulance service.

Participants: 51 unresponsive adult patients with blood glucose levels $\leqslant 4 \mathrm{mmol} / \mathrm{l}$.

Intervention: $5 \mathrm{~g} \mathrm{(50} \mathrm{ml)} \mathrm{intravenous} \mathrm{aliquots} \mathrm{of} \mathrm{10 \%} \mathrm{dextrose} \mathrm{or} 5 \mathrm{~g}(10 \mathrm{ml})$ intravenous aliquots of $50 \%$ dextrose to a maximum dose of $25 \mathrm{~g}$.

Main outcome measures: To compare for each dextrose concentration the time to achieve a Glasgow Coma Scale (GCS) score of 15, and the dose required to obtain a blood glucose level of $\geqslant 4.5 \mathrm{mmol} / \mathrm{l}$. Results: There were no statistically significant differences between the groups with regard to age or sex, median pretreatment GCS, pretreatment blood glucose level, or proportion of patients with insulin dependent diabetes. Following treatment, there were no statistically significant differences in median time to recovery (8 minutes), median post-treatment GCS, or number of subjects experiencing a further hypoglycaemic episode within 24 hours (four per group). The median total dose of dextrose administered was significantly less with the $10 \%$ concentration $(10 \%=10 \mathrm{~g}, 50 \%=25 \mathrm{~g}, \mathrm{p}<0.001)$ and median posttreatment blood sugar levels were also significantly lower $(10 \%=6.2 \mathrm{mmol} / \mathrm{l}$ and $50 \%=9.4 \mathrm{mmol} / \mathrm{l}$, $p=0.003)$. There were no reports of extravasation injuries in either group.

Conclusions: Dextrose 10\% delivered in $5 \mathrm{~g}(50 \mathrm{ml})$ aliquots is administered in smaller doses than dextrose $50 \%$ delivered in $5 \mathrm{~g} / 10 \mathrm{ml}$ aliquots, resulting in lower post-treatment blood glucose levels. We therefore recommend it as the intravenous treatment of choice for adult hypoglycaemia.
B efore 1999, 50\% dextrose and glucagon were the principal treatments available to UK emergency ambulance personnel caring for unconscious or unresponsive hypoglycaemic patients. Dextrose $50 \%$ is a hypertonic solution of glucose available in prefilled syringes containing $25 \mathrm{~g}$ glucose in $50 \mathrm{ml}$ water (IMS mini-jet, International Medication Systems (UK), Leatherhead, Surrey, England). In south-east Wales, at the time of this study, it was administered intravenously in 5-10 g (10-20 ml) increments, titrated against effect after confirming hypoglycaemia by capillary or venous blood sugar level.

High concentrations of glucose can cause cerebral oedema and death in children. ${ }^{1}$ In 1999, a revised UK paramedic training syllabus and manual were introduced and in 2000, the Joint Royal Colleges Ambulance Liaison Committee (JRCALC) published its prehospital treatment guidelines. ${ }^{23}$ Both recommended $10 \%$ dextrose for the reversal of hypoglycaemia in children and pregnant women. Subsequently, $10 \%$ dextrose became available in most UK ambulances and its use was recommended for the reversal of all hypoglycaemic episodes. ${ }^{4}$

A literature search retrieved a number of papers evaluating the use of $50 \%$ dextrose and glucagon..$^{5-12}$ However, no research was found that evaluated $10 \%$ dextrose for the treatment of hypoglycaemia, although one paper reported that, as with any hypertonic solution, extravasation injury is possible. ${ }^{13}$

This randomised controlled trial aimed to compare the efficacy and safety of $5 \mathrm{~g}$ aliquots of $10 \%$ and $50 \%$ dextrose in the out of hospital treatment of adult hypoglycaemic patients.

\section{METHODS}

\section{Participants}

We included hypoglycaemic patients aged 18 years or over from south-east Wales (UK), whose level of consciousness and ability to cooperate did not allow administration of oral carbohydrates, whose blood sugar was $\leqslant 4 \mathrm{mmol} / \mathrm{l}$, and in whom intravenous access had been gained in three or fewer attempts. We excluded conscious, cooperative patients, who were able to take oral carbohydrate or who were administered dextrose, glucagon, or Hypostop (Bio-diagnostics Ltd, Upton-on-Severn, Worcestershire, UK) before the arrival of the paramedics.

\section{Interventions}

To be consistent with the existing South-East Wales paramedic protocol for $50 \%$ dextrose, we randomised patients to receive either $10 \%$ or $50 \%$ dextrose in $5 \mathrm{~g}$ increments. This was considered appropriate as it allowed us to compare equivalent doses of the two solutions. To ensure that the dose of $10 \%$ dextrose was measured accurately, the paramedics used a syringe attached to a three-way tap to draw up $50 \mathrm{ml}$ aliquots from a $500 \mathrm{ml}$ infusion bag attached to a giving set. The $10 \mathrm{ml}$ aliquots administered to the $50 \%$ dextrose group were measured using $5 \mathrm{ml}$ calibration markings on the prefilled syringes. The paramedics were instructed to administer the $5 \mathrm{~g}$ bolus and wait for one minute before administering subsequent aliquots, until either the Glasgow Coma Scale (GCS) score had returned to 15 or the maximum cumulative dose of $25 \mathrm{~g}$ of dextrose had been administered. Time taken to regain GCS 15 was calculated from the time the first incremental dose was administered. 


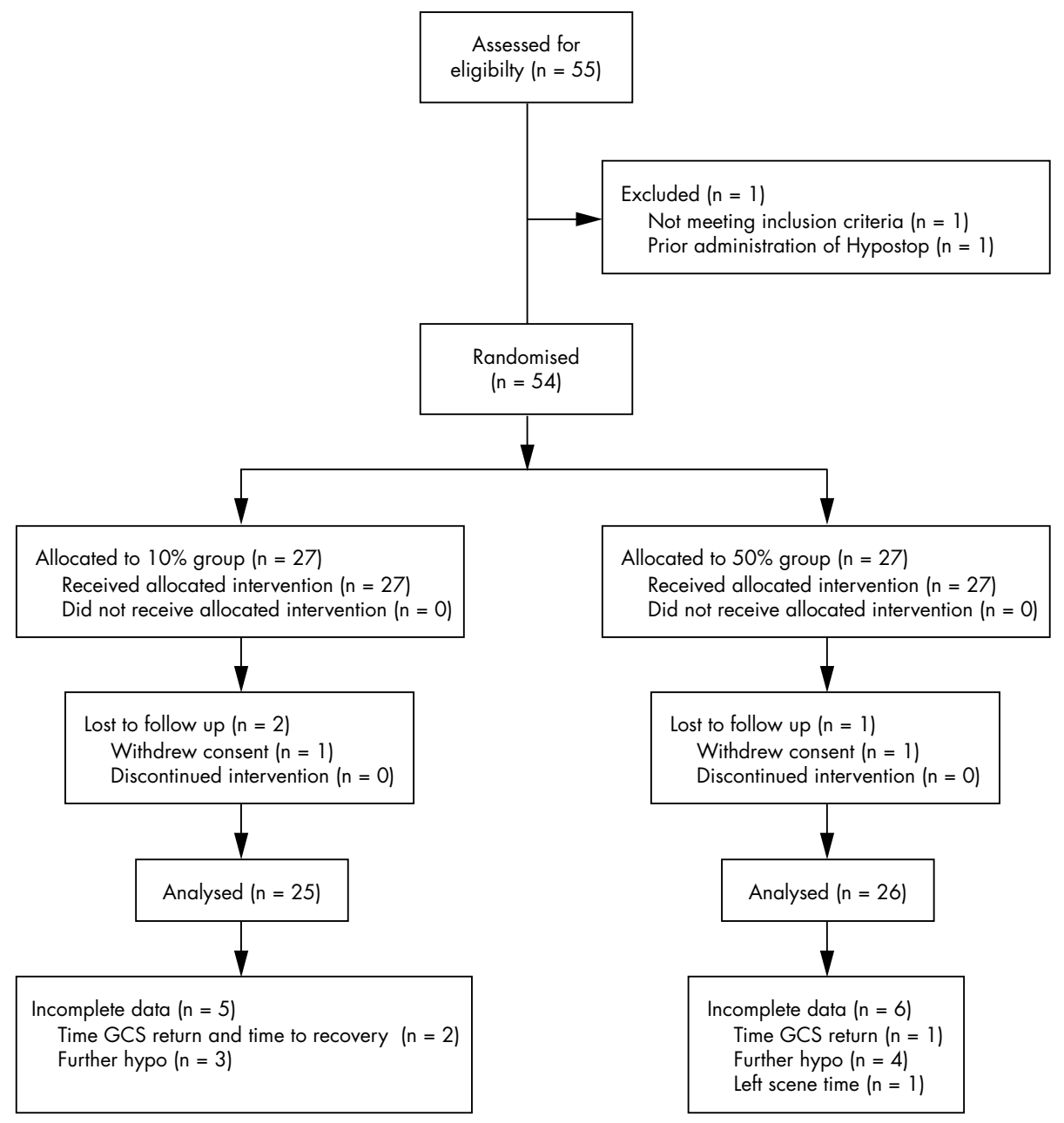

Figure 1 CONSORT flow chart illustrating the recruitment of patients for the present randomised controlled trial. hypo, hypoglycaemic episode in 24 hours.

\section{Outcomes}

Our key outcome measure for this study was intergroup comparison of the time taken to regain a GCS score of 15 following the administration of two concentrations of dextrose. Secondary outcome measures included post-treatment blood glucose levels, the total dose of dextrose given, and the time required to achieve a capillary blood sugar level of $\geqslant 4.5 \mathrm{mmol} / \mathrm{l}$, measured using Roche Accu-Check "Advantage" blood glucose meters and test strips (Roche Diagnostics Ltd, Bell Lane, Lewes, East Sussex, UK). The paramedics were asked to record incidences of extravasation and to score the convenience of administering each concentration of dextrose using a Likert scale. The researchers followed up all patients to determine whether there had been a recurrent episode of hypoglycaemia within 24 hours of treatment.

\section{Consent}

Due to the confused or unconscious state of hypoglycaemic patients it was not possible to obtain informed consent from the participants prior to recruitment into the trial. Instead, when they were recovered and oriented after treatment, the paramedics informed them that they had been recruited for a study that was comparing the efficacy of two different concentrations of dextrose. Each participant was given an information pack describing the trial with a form and preaddressed envelope so that participants could withdraw their data from the study at any time. Ethical approval was obtained from the Bro Taf Health Authority Local Research Ethics Committee.

\section{Sample size}

Following a pilot study, it was established that a total sample size of 50 was required ( 25 subjects per group) to detect a three minute difference between the groups in a return to full consciousness (GCS 15), with power of 0.85 and $\alpha$ of 0.05 .

\section{Randomisation}

A total of 240 study forms (120 per group) identifying the concentration of dextrose to be administered were prerandomised for order using SPSS (version 10.0.5) and assigned a unique sequential number. Each form was put in an opaque envelope and packed in consecutively numbered groups of 10, which were then placed in participating ambulance service vehicles. Following confirmation that a subject met the inclusion criteria, paramedics responsible for their care opened the lowest numbered envelope remaining in the vehicle's pack and administered the dextrose concentration detailed on the study form inside. The randomisation sequence was concealed and held by one of the chief investigators until recruitment was completed.

\section{Blinding}

Due to the differences in appearance of the two formulations of dextrose it was not possible to blind the paramedics to the concentration of dextrose given. 
Table 1 Comparison of the demographic data of the two study groups. Values are median (range, interquartile range)

\begin{tabular}{|c|c|c|c|}
\hline & $10 \%$ Group $(n=25)$ & $50 \%$ Group $(n=26)$ & Difference, $p$ value \\
\hline $\begin{array}{l}\text { Age } \\
\text { Pretreatment GCS } \\
\text { Pretreatment blood glucose (mmol/l) }\end{array}$ & $\begin{array}{l}56(22 \text { to } 93,38 \text { to } 74) \\
4(3 \text { to } 14,3 \text { to } 8) \\
1.50(0.00 \text { to } 3.80,1.20 \text { to } 1.80)\end{array}$ & $\begin{array}{l}54(22 \text { to } 81,43 \text { to } 66) \\
6(3 \text { to } 14,3 \text { to } 12) \\
1.40(0.00 \text { to } 3.70,0.78 \text { to } 1.83)\end{array}$ & $\begin{array}{l}-2, p=0.692 \\
+2, p=0.400 \\
-0.1, p=0.317\end{array}$ \\
\hline & Proportion (\%) & Proportion (\%) & Difference $(95 \% \mathrm{Cl}, \mathrm{p})$ \\
\hline $\begin{array}{l}\text { Male } \\
\text { Insulin dependent diabetes }\end{array}$ & $\begin{array}{l}15 / 25(60) \\
21 / 25(84)\end{array}$ & $\begin{array}{l}16 / 26(62) \\
22 / 26(85)\end{array}$ & $\begin{array}{l}+2 \%(-28 \text { to }+25 \%, p=1) \\
+1 \%(-22 \text { to }+21 \%, p=1)\end{array}$ \\
\hline
\end{tabular}

\section{Statistical methods}

We used SPSS to conduct the Mann-Whitney U test for intergroup comparisons of age, pretreatment and posttreatment GCS and blood sugar, total dose of dextrose administered, time to recovery, time on scene, and ease of administration. StatsDirect (version 2.2.78, CamCode, Ashwell, UK) was used to calculate $\mathrm{p}$ values and $95 \%$ confidence intervals for intergroup differences in proportions with regard to sex, insulin dependent diabetes, and posttreatment recurrent hypoglycaemia.

\section{RESULTS}

\section{Demographics and recruitment}

We collected the data for this study from 28 October 2002 to 25 October 2003. See fig 1 for details of patient recruitment. A total of four randomisation envelopes were opened out of sequence. In two cases this did not alter the dextrose concentration that should have been administered had the correct envelope been selected. No evidence of a deliberate attempt to break the randomisation sequence was identified. We analysed the data on an intention to treat basis. We are aware of one protocol violation. One of the participants in the $10 \%$ group received a total dose of $30 \mathrm{~g}$ rather than $25 \mathrm{~g}$. This was a result of a paramedic failing to use a three-way tap and setting up a free running drip instead.

There were no significant differences between the groups in age or sex characteristics or the number of patients with insulin dependent diabetes. Pretreatment GCS and blood glucose levels were also similar in both groups (table 1).

\section{Outcome data}

We analysed the data on an intention to treat basis to recovery of normal consciousness. There were no significant differences between the groups in time to recovery to maximum consciousness (GCS of 15), median post-treatment GCS, or the proportion of participants experiencing a further hypoglycaemic episode within 24 hours.
Table 3 Analysis of patients not achieving a Glasgow Coma Scale (GCS) score of 15

\begin{tabular}{|c|c|c|c|c|c|}
\hline \multirow{2}{*}{$\begin{array}{l}\text { Unique } \\
\text { identifier }\end{array}$} & \multirow[b]{2}{*}{ Group } & \multicolumn{2}{|c|}{ Blood sugar } & \multicolumn{2}{|c|}{ GCS } \\
\hline & & Pre & Post & Pre & Post \\
\hline 82 & $10 \%$ & 1.3 & 11.4 & 3 & 6 \\
\hline 212 & $10 \%$ & 3.8 & 9.7 & 9 & 9 \\
\hline 23 & $50 \%$ & 1.1 & 8.7 & 3 & 3 \\
\hline
\end{tabular}

Time on scene was moderately higher for the $10 \%$ dextrose group, and paramedics rated administration of $10 \%$ dextrose as being slightly less easy than for the 50\% solution. However, neither finding reached statistical significance. There were no reported incidences of extravasation in either group.

Both the median total dose of dextrose administered and post-treatment blood sugar level were significantly higher in the $50 \%$ group, and these subjects were more likely to have received the maximum permitted dose of $25 \mathrm{~g}$ (table 2 ).

An exploratory analysis of patients without a maximum GCS score of 15 following treatment is shown in table 3. Although all three patients had euglycaemic post-treatment blood sugar levels, all required hospital admission. One of these patients was suspected of being under the influence of illegal drugs, one was a known alcoholic, and one had a serious intercurrent urinary tract infection.

\section{DISCUSSION}

We did not find any difference in the efficacy of treatment between the two groups in the present study. However, despite both cohorts having similar GCS and blood sugar levels before treatment, subjects in the $50 \%$ group received a median of $15 \mathrm{~g}$ more glucose than those in the $10 \%$ group, and subsequently had post-treatment blood glucose levels that were a median of $3.2 \mathrm{mmol} / \mathrm{l}$ higher. Patients

Table 2 Differences in outcome measures between the two study groups. Values are median (range, interquartile range)

\begin{tabular}{|c|c|c|c|}
\hline & $10 \%$ Group $(n=25)$ & $50 \%$ Group $(n=26)$ & Difference, $p$ value \\
\hline $\begin{array}{l}\text { Total dose of dextrose }(\mathrm{g}) \\
\text { Post-treatment blood glucose (mmol/l) } \\
\text { Post-treatment GCS } \\
\text { Time to GCS } 15 \text { (min) } \\
\text { Time on scene (min) } \\
\text { Ease of administration score }\end{array}$ & $\begin{array}{l}10(5 \text { to } 30,10 \text { to } 15) \\
6.20(4 \text { to } 17,5.15 \text { to } 9.10) \\
15(6 \text { to } 15,15 \text { to } 15) \\
8(1 \text { to } 30,5 \text { to } 15) \\
40(13 \text { to } 75,30 \text { to } 51) \\
2(1 \text { to } 4,1 \text { to } 3)\end{array}$ & $\begin{array}{l}25(10 \text { to } 25,15 \text { to } 25) \\
9.40(4.30 \text { to } 18.50,8.28 \text { to } 11.60) \\
15(3 \text { to } 15,15 \text { to } 15) \\
8(2 \text { to } 19,4 \text { to } 11) \\
35(15 \text { to } 61,23 \text { to } 45) \\
1(1 \text { to } 5,1 \text { to } 2)\end{array}$ & $\begin{array}{l}+15, p<0.001 \\
+3.2, p=0.003 \\
0, p=0.400 \\
0, p=0.733 \\
-5, p=0.162 \\
-1, p=0.142\end{array}$ \\
\hline & Proportion (\%) & Proportion (\%) & Difference ( $95 \% \mathrm{Cl}$, p value) \\
\hline $\begin{array}{l}\text { Subjects receiving the maximum permitted } \\
\text { dose of } 25 \mathrm{~g} \\
\text { Subjects with a post-treatment GCS of }<15 \\
\text { Subjects with a further hypoglycaemic } \\
\text { episode within } 24 \mathrm{~h}\end{array}$ & $\begin{array}{l}3 / 25(12 \%) \\
2 / 25(8 \%) \\
4 / 22(18 \%)\end{array}$ & $\begin{array}{l}17 / 26(65 \%) \\
1 / 26(4 \%) \\
4 / 22(18 \%)\end{array}$ & $\begin{array}{l}+53 \%(+28 \text { to }+72 \%, p<0.0001) \\
-4 \%(-12 \text { to }+22 \%, p=0.360) \\
0 \%(-24 \text { to }+24 \%, p=1)\end{array}$ \\
\hline
\end{tabular}


administered 50\% dextrose were more likely to have received the maximum dose of $25 \mathrm{~g}$ than those given the $10 \%$ concentration. The reasons for this are unclear, but may be related to the presentation of the $50 \%$ solution or to usual practice before the trial. It is also possible that the pharmacokinetics of the two solutions are different, and that $50 \%$ dextrose delivered in $5 \mathrm{~g}(10 \mathrm{ml})$ boluses has a slower onset of action, encouraging the administration of additional increments before initial aliquots have taken effect.

Two of the subjects contacted by the researchers after treatment reported that before the study they had often had difficulty bringing their blood glucose back to their expected usual level after being treated by paramedics using 50\% dextrose. This might imply that the lower cumulative doses administered with the $5 \mathrm{~g}(50 \mathrm{ml})$ aliquots of $10 \%$ dextrose could assist patients in controlling their post-treatment blood sugar levels. Evidence suggests that administration of dextrose can have a detrimental effect on patients at risk of cerebral ischaemia, such as victims of stroke, cardiac arrest, or head trauma. ${ }^{7}$ Avoidance of hyperglycaemia has a neuroprotective effect and reduces mortality and morbidity in the critically ill. ${ }^{14}{ }^{15}$ The relatively lower post-treatment blood sugar levels associated with the use of $10 \%$ dextrose administered in $5 \mathrm{~g}(50 \mathrm{ml})$ aliquots may, therefore, offer a safer option for the treatment of hypoglycaemia in these categories of patient.

\section{Limitations of the study}

Follow up data were not available for three patients in the $10 \%$ group and four in the $50 \%$ group, but these missing data would not have significantly changed this study's primary finding. The total number of patients who presented with hypoglycaemia in the study area during the trial period was not available. Although this did not influence the randomisation process, it is possible that the outcome of those patients not recruited for the trial could have altered its results had they been included.

\section{CONCLUSIONS}

Dextrose $10 \%$ administered in $5 \mathrm{~g}(50 \mathrm{ml})$ aliquots was found to be as effective and safe as 50\% dextrose delivered in $5 \mathrm{~g}$ $(10 \mathrm{ml})$ aliquots. Patients in the $10 \%$ dextrose group received a median of $15 \mathrm{~g}$ less glucose than those in the $50 \%$ group, were less likely to receive the maximum permitted dose, and consequently had post-treatment blood glucose levels that were $3.2 \mathrm{mmol} / \mathrm{l}$ lower on average. We therefore recommend $10 \%$ dextrose administered in $5 \mathrm{~g}(50 \mathrm{ml})$ aliquots as the first choice intravenous therapy for the treatment of hypoglycaemia in adults.

\section{ACKNOWLEDGEMENTS}

The authors would like to thank all the paramedics who participated in this study, in particular, K Dwyer who asked the question "If we can use $10 \%$ dextrose for pregnant females, why can't we use it for all adults?" A Smith, K Roberts, and K Pitt helped identify relevant papers. $\mathrm{R}$ Whitfield provided expert advice about the randomisation strategy and E Green, P Burrows, and P Wilkins helped with preparation of the data collection forms.

\section{AUTHORS' CONTRIBUTIONS}

$\mathrm{C}$ Moore had the idea for the study and collected the data. M Woollard and C Moore designed the study, analysed the data, and wrote and edited this paper.

\section{Authors' affiliations}

C Moore, Pre-hospital Emergency Research Unit, Welsh Ambulance Services NHS Trust, Lansdowne Hospital, Cardiff, UK

M Woollard, Faculty of Pre-hospital Care Research Unit, the James Cook University Hospital/University of Teesside, Middlesbrough, UK

This research was funded by a grant of $£ 2000$ from the Wales Office of Research and Development support for science allocation to the Welsh Ambulance Services NHS Trust.

Competing interests: none declared

\section{REFERENCES}

1 Advanced Life Support Group. Pre-hospital Paediatric Life Support. London: BMJ Publications, 1999:158-9.

2 Institute of Health Care and Development. Paramedic Training Manual. Bristol: Institute of Health Care and Development, 1999

3 Joint Royal Colleges Ambulance Liaison Committee. Medical Emergencies. In: Joint Royal Colleges Ambulance Liaison Committee. Prehospital Clinical Guidelines. London: Joint Royal Colleges Ambulance Liaison Committee, 2000.

4 Joint Royal Colleges Ambulance Liaison Committee. Medical Emergencies In: Joint Royal Colleges Ambulance Liaison Committee. Prehospital Clinical Guidelines 2002 (version 2.2). London: Joint Royal Colleges Ambulance Liaison Committee, 2002.

5 Collier A, Steedman J, Patrick AW, et al. Comparison of intravenous glucagon and dextrose in treatment of severe hypoglycaemia in an accident and emergency department. Diabetes Care 1987;10:712-15.

6 Patrick AW, Collier A, Hepburn DA, et al. Comparison of intramuscular glucagon and intravenous dextrose in the treatment of hypoglycaemic coma in an accident and emergency department. Arch Emerg Med 1990;7:73-7.

7 Browning RG, Olsen DW, Steuven HA, et al. 50\% dextrose: antidote or toxin? Ann Emerg Med 1990;19:683-7.

8 Howell MA, Guly HR. A comparison of glucagon and glucose in pre-hospital hypoglycaemia. J Accid Emerg Med 1997;14:30-2.

9 MacCuish AC, Munro JF, Duncan $\sqcup$. Treatment of hypoglycaemic coma with glucagon, intravenous dextrose and mannitol infusion in a hundred diabetics. Lancet 1970;2:946-9.

10 Carstens S, Sprehn M. Prehospital treatment of severe hypoglycaemia: a comparison of intramuscular glucagon and intravenous glucose. Prehospital Disaster Med 1998;13:44-50.

11 Vukmir RB, Paris PM, Yealy DM. Glucagon: prehospital therapy for hypoglycaemia. Ann Emerg Med 1991;20:375-9.

12 Steel JM, Allwinkle J, Moffat R, et al. Use of lucozade and glucagon by ambulance staff for treating hypoglycaemia. BMJ 1992;304:1283-4.

13 Gault DT. Extravasation injuries. Br J Plast Surg 1993;46:91-6.

14 Hans $\mathbf{P}$, Bonhomme $\mathrm{V}$. The rationale for perioperative brain protection. Eur J Anaesthesiol 2004;21:1-5.

15 Robinson LE, Van Soeren MH. Insulin resistance and hyperglycemia in critical illness: role of insulin in glycemic control. AACN Clin Issues 2004; 15:45-62. 